\title{
Multiscale Geomechanical Behavior of Fiber-Reinforced Cementitious Composites Under Cyclic Loading Conditions-A Review
}

\author{
Javaugh McLean ${ }^{1,2}$ and Liang Cui ${ }^{1,2 *}$ \\ ${ }^{1}$ Department of Civil Engineering, Lakehead University, Thunder Bay, ON, Canada, ${ }^{2}$ State Key Laboratory of Geohazard \\ Prevention and Geoenvironment Protection, Chendu, China
}

As construction materials, cementitious composites such as cemented paste backfill (CPB), cemented soil, and concrete may be subjected to extreme dynamic loadings including impact, blast, and/or seismic loads during their service life. To improve

OPEN ACCESS

Edited by:

Erol Yilmaz,

Recep Tayyip Erdoğan University,

Turkey

Reviewed by:

Lijie Guo,

Beijing General Research Institute of Mining and Metallurgy, China

Hasan Eker,

Karabük University, Turkey

Jingping Qiu,

School of Resources and Civil Engineering, Northeastern University,

China

*Correspondence:

Liang Cui

liang.cui@lakeheadu.ca

Specialty section:

This article was submitted to

Structural Materials,

a section of the journal

Frontiers in Materials

Received: 15 August 2021 Accepted: 06 September 2021 Published: 28 September 2021

Citation:

McLean J and Cui L (2021) Multiscale

Geomechanical Behavior of Fiber-

Reinforced Cementitious Composites

Under Cyclic Loading

Conditions $-A$ Review.

Front. Mater. 8:759126.

doi: $10.3389 /$ fmats.2021.759126 mechanical performance under dynamic loadings, fiber reinforcement technique has been considered a promising approach and extensively used in practice. In this manuscript, a new perspective on the multiscale geomechanical behavior of fiberreinforced cementitious composites (FRCC) is provided through a comprehensive review on the macroscale constitutive behavior and the associated mechanical properties, and microscale failure processes under cyclic tensile, shear, and compressive loading conditions. For the macroscale mechanical response, this review includes a detailed analysis of the state-of-the-art research in stress-strain behaviors including pre- and post-peak response and hysteretic behaviors. Moreover, the effects of pore water pressure on the dynamic response of soft FRCCs such as CPB are discussed. Furthermore, the link between microscale crack propagation (including the formation of the interfacial transition zone and fracture process zone) and damage accumulation is established for each type of cyclic loading condition. In addition, a critical discussion on the future development of fiber reinforcement is conducted as well. Therefore, this review not only offers guidance and references to the experimental investigation on the multiscale behavior of FRCCs under cyclic loadings, but also promotes the further development of fiber reinforcement techniques.

Keywords: multiscale, fiber reinforcement, cyclic loading, cementitious materials, crack propagation

\section{INTRODUCTION}

As a type of construction material, cementitious composites are commonly subjected to complex field loading conditions during their service life (Cui and Fall, 2015; Wu et al., 2016; Lin et al., 2020; $\mathrm{Xu}$ et al., 2020). As a result, the external loadings may cause the development of compressive, tensile and/or shear stresses in the porous mixture and thus dominate the failure processes at the macroscale (Xu et al., 2019; Libos and Cui, 2020; Liu et al., 2020). However, irrespective of the external loading conditions, the crack initiation is commonly associated with the local stress concentration near defects at the microscale (Wang et al., 2021b). Since mechanical stability is one of the most critical design criteria, cementitious composites are required to offer adequate stress resistance and sufficient 
tolerance for permanent deformation in engineering applications. However, as a type of brittle material, cementitious composites such as cemented paste backfill (CPB), cemented soil, and concrete are commonly featured by the limited strainhardening behavior and weak post-peak performance (Cui and Fall, 2016b; Li et al., 2018b). To improve the mechanical behavior and properties of cementitious composites, it has been found that reinforcement through the addition of short fibers is a promising technique (Dönmez et al., 2020; Cao et al., 2021; Huang et al., 2021b; Külekçi, 2021; Xue et al., 2021). This is because fibers in cementitious materials are able to produce the bridging forces across cracks in the porous matrix (Cao et al., 2019; Xue et al., 2019; Cao et al., 2020; Huang et al., 2021b), thus, acting as crack arresters at the microscale. Correspondingly, the fiber-reinforced cementitious composites (FRCC) can withstand larger plastic deformation and improve material ductility (Li et al., 2018b; Cao et al., 2020). Subsequently, the macroscale stress-strain behavior, especially post-peak behavior, can be considerably improved and becomes more favorable for engineering applications. Therefore, understanding of multiscale geomechanical behaviors of FRCC plays a key role in the safe and optimum design of FRCC.

However, the performance of FRCC is dependent on the inservice and environmental loading conditions. Previous studies show that FRCC can demonstrate distinct mechanical behaviors under monotonic and cyclic loadings (Boulekbache et al., 2016; Dönmez et al., 2020). For example, cyclic loading can cause a progressively decrease in load-carrying capacity of FRCC. Such degradation of load-carrying capacity can be partially attributed to cyclic loading-induced damage accumulation in the porous matrix (Hu et al., 2018). Therefore, the resultant material degradation causes a poor engineering performance of FRCC relative to that under quasi-static loading conditions. Furthermore, the fibers embedded into the matrix can suffer severe extrusion or even rupture during the cyclic loading process, which causes a reduction in the crack bridging capacity (Guo et al., 2020; Zhou et al., 2020). Consequently, FRCC could show different failure patterns, material properties, and constitutive behaviors under cyclic loading conditions. Accordingly, the obtained findings about the quasi-static behavior may be invalid for FRCC under cyclic loading conditions.

Additionally, FRCC may be subjected to various types of dynamic loadings in the field and thus cause different stresses inside the FRCC. For example, as one of the most critical components of a building structure, fiber-reinforced concrete columns such as bridge piers are designed to withstand large axial and shear forces, especially in seismic regions (Wang et al., 2019). Correspondingly, the resultant dynamic compressive and shear stresses govern the stability of FRCC. Furthermore, fiberreinforced shotcrete (FRS) linings have been widely used in underground mines and civil tunnels to prevent the occurrence of many disasters such as caving, slabbing, and rockburst as a result of complex field loadings (Bernard, 2015; Qiu et al., 2020). As a result, FRS is commonly exposed to high tensile and compressive stresses due to vibrations from blasting operations, which may cause various dynamic failures such as the cracking of the shotcrete lining, failure along the shotcrete-rock

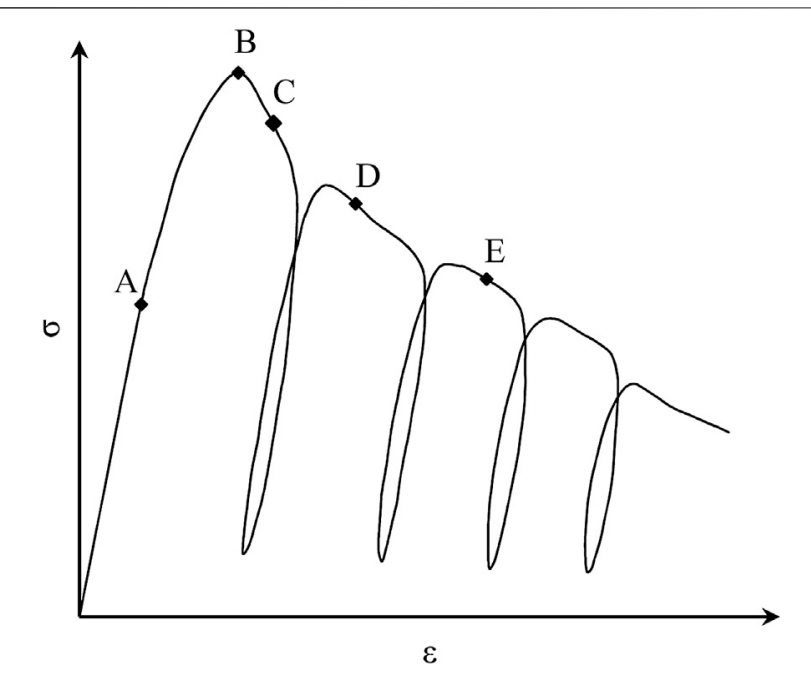

FIGURE 1 | Typical stress-strain curve of FRCC under cyclic tensile loading.

interface, and flexural failure of the shotcrete (Sjölander et al., 2020). In addition, fiber reinforcement technique has attracted increasing attention in the optimal design of CPB used in the underground mines ( $\mathrm{Ma}$ et al., 2016). Once placed into the underground excavations, the hardened backfilling materials are required to provide adequate secondary ground support and thus to maintain the stability of surrounding rock mass (Cui and Fall, 2017b; Cui and Fall, 2018; Wang et al., 2020). Consequently, multiaxial and complex stress states can arise in the backfilling materials (Yilmaz, 2018; Chen et al., 2019; Cui and Fall, 2019). Therefore, to improve the understanding of the multiscale geomechanical behaviors of FRCC under dynamic loadings, this study aims to provide a critical review of 1) the cyclic compressive, tensile, and shear behaviors, 2) the failure patterns, and 3) the mechanical properties of FRCC under cyclic loadings, which can benefit the safe and optimal design of FRCC under cyclic loading conditions (Rena et al., 2016). Future work related to the multiscale fiber reinforcement technique is also suggested through the identification of the research gap in this field of knowledge.

\section{MULTISCALE GEOMECHANICAL BEHAVIOR OF FIBER-REINFORCED CEMENTITIOUS COMPOSITES UNDER CYCLIC LOADINGS}

The constitutive behavior of FRCC is commonly evaluated by the stress-strain curves obtained from the conventional cyclic loading-unloading tests. This is because assessing the cyclic stress-strain curves could not only provide insight into the pre- and post-peak behavior of FRCC but also its mechanical properties. The obtained stress-strain behavior and mechanical properties can be directly used in the quantitative analysis such as 
stability assessment and strength-based design of FRCC at field scale. In addition, the failure patterns can be identified by macroscale non-destructive evaluation methods such as ultrasound and digital image correlation (DIC) technique and microstructure observation analysis such as scanning electron microscopy (SEM) and X-ray computed tomography (CT) (Li et al., 2018a; Wu et al., 2019; Cao et al., 2021). To further understand the multiscale geomechanical behaviors of FRCC under dynamic loading conditions, a critical review is presented in the following subsections to provide deep insights into the cyclic tensile, shear, and compressive response of FRCC. More specifically, this paper focuses mainly on three aspects: the constitutive behavior, failure patterns, and the mechanical properties of FRCC under cyclic loading conditions.

\section{Cyclic Tensile Behavior of Fiber-reinforced Cementitious Materials}

Due to the effects of fiber reinforcement, the constitutive tensile behavior of FRCC under cyclic loading is featured by an ascending branch akin to the plain cementitious material and an enhanced post-peak branch (Liu et al., 2019). Figure 1 represents a typical stress-strain curve that can be used to explain the damage process of FRCC under cyclic loading conditions. For the pre-peak behavior (path $0 \mathrm{~B})$, the material exhibits high elasticity making it difficult to spot the hysteretic loops (Li et al., 2018a). This is because the crack-bridging capacity of the fibers is not activated until the first crack appears; at first-crack stress, the cracks start to propagate in the porous matrix. However, the capacity of fibers bridging such cracks promotes the local stress concentration and causes the further propagation of microcracks. Moreover, point A (Figure 1) signals a transition point on the stress-strain curve from linear to non-linear regimes due to the multi-cracking characteristic afforded by the fibers. When the fibers in the weakest crack have failed, the crack localizes, and the material exhibits a softening behavior (Jun and Mechtcherine, 2010). Correspondingly, the peak point B (Figure 1) is followed by a noticeable stress drop with distinguished unloading and reloading paths that highlight the hysteretic behavior of FRCC under cyclic tensile loading (Boulekbache et al., 2016). However, in the post-peak region (paths $\mathrm{CD}$ and $\mathrm{DE}$ in Figure 1), fiber sliding, and pull-out mechanisms are the main contributors to the energy dissipation capacity of FRCC, which causes more defined hysteretic loops with increasing load cycles (Xu et al., 2018a). Conversely, the sudden drop after the peak stress is associated with the fracturing of the cementitious matrix. The cracks begin to propagate and coalesce into the main crack causing severe deformation of fibers, fracturing of fibers, and debonding of fibers with the continuously increasing displacement and loading cycles. Therefore, it has been widely accepted that fiber reinforcement in cementitious composites mainly affects the post-peak performance, specifically to transform the brittle nature of cementitious matrix to a more ductile one with improved mechanical properties (Pakravan and
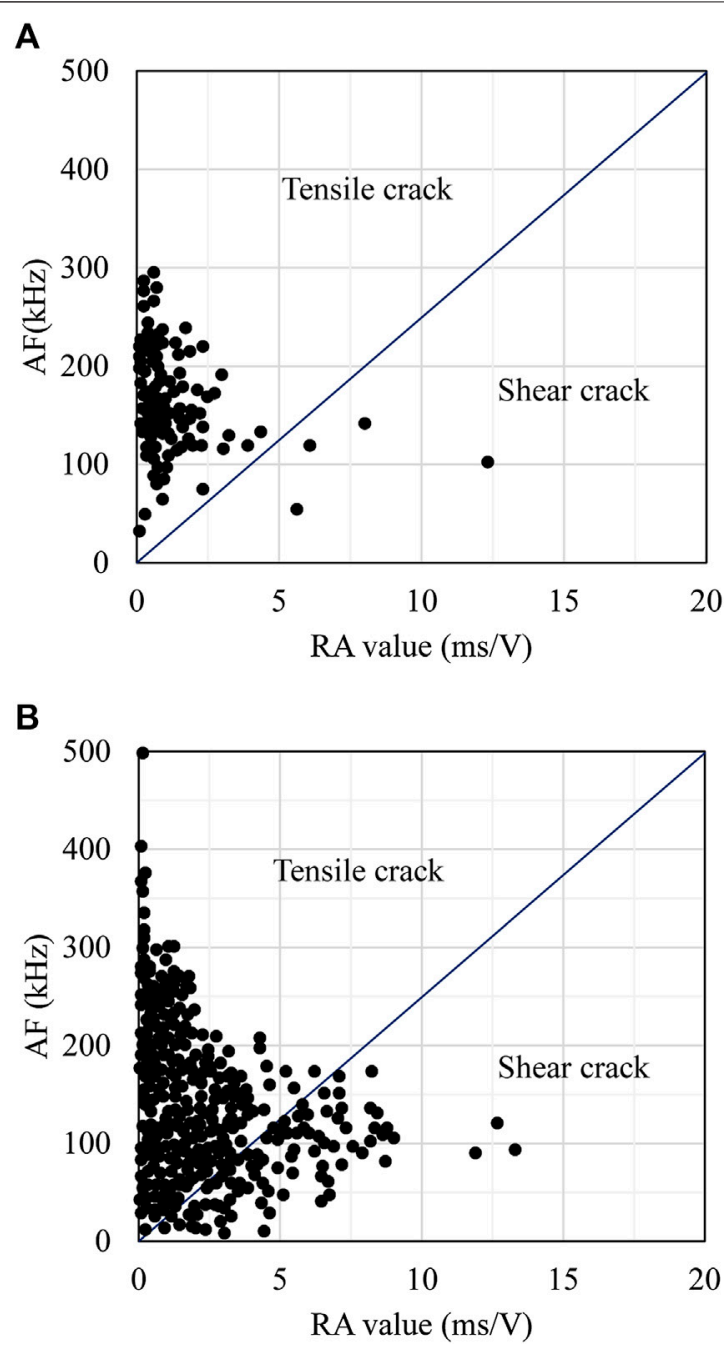

FIGURE 2|Type of cracks generated in the cementitious material under cyclic tensile loading: (A) without fiber reinforcement, and (B) with fiber reinforcement (Li et al., 2018a).

Ozbakkaloglu, 2019). In Particular, previous studies (Caverzan et al., 2012; Khlef et al., 2019) have successfully demonstrated the benefits of incorporating fibers into the cementitious matrix to improve the cyclic tensile behavior of FRCC. The results confirmed that the integration of fibers into cementitious matrix significantly improves peak stress, peak strain, ductility, and material toughness. Furthermore, the degradation rate of material properties such as stiffness is significantly alleviated by the inclusion of fibers with increasing volume fraction or aspect ratio (Chung et al., 2021).

In addition to the constitutive behavior of FRCC, understanding the bridging behavior and any synergy between these bridging mechanisms in FRCC is vital to determining its crack-restraining capabilities. The acoustic emission (AE) technique, as a non-destructive testing approach, has been widely adopted for the investigation of local damage in 


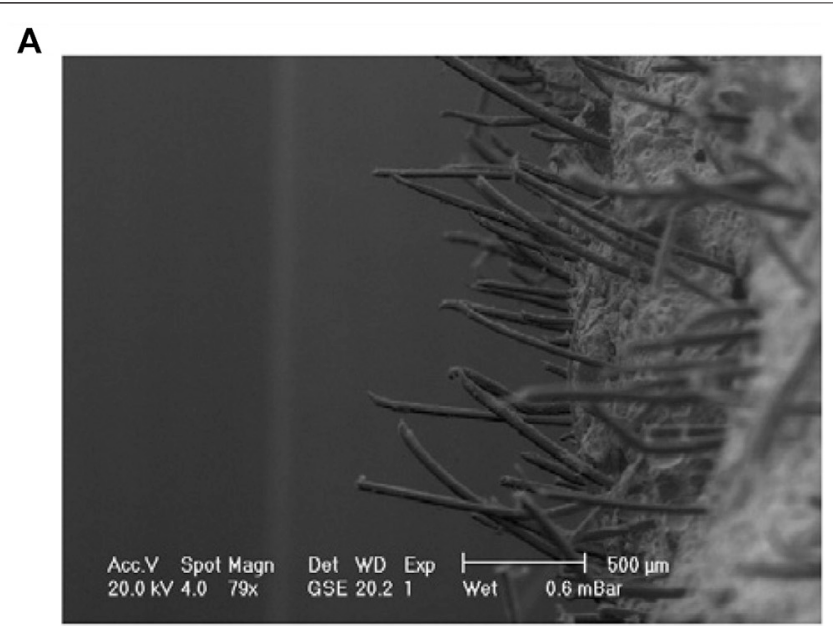

B

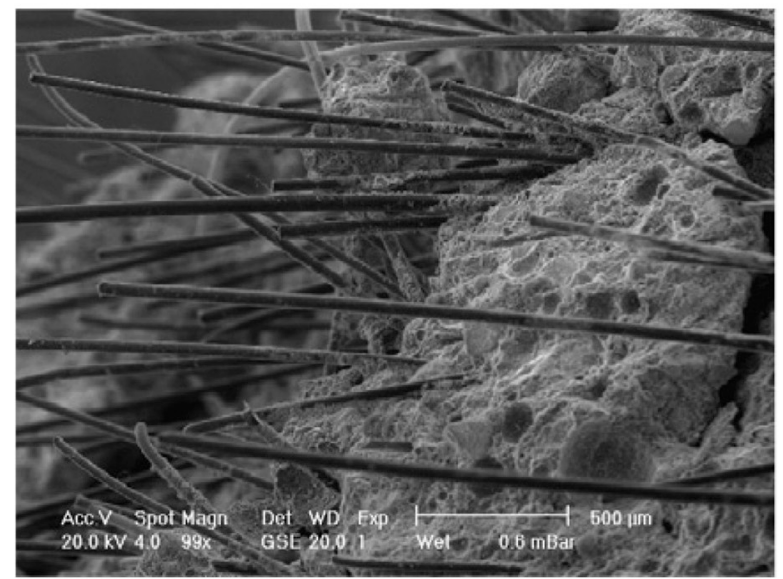

FIGURE 3 | Comparison of pullout lengths of fibers embedded in the cementitious materials under (A) monotonic loading, and (B) cyclic loading (Mechtcherine et al., 2011).

cementitious materials. This is because AE indices such as the average frequency and rise angle can be used to characterize the mode of cracking and quantify the damage level in FRCC (Aggelis et al., 2011). For example, Li et al. (2018a) and Aggelis (2011) utilized AE technique to investigate cracking modes of FRCC under cyclic tensile loadings. As shown in Figure 2, it has been found that compared with plain concrete FRCCs produce far more $\mathrm{AE}$ events and show clear signs of crack propagation due to the fiber reinforcement. Moreover, it has also been found that a cementitious composite subjected to complex loadings experiences tensile cracks in the initial stage of the damage process while shear cracks dominate in the later stages (Yuyama et al., 1999). In addition, Soulioti et al. (2009) described each fiber pull-out incident as a potential AE event, and these events increase with the fiber volume content, which clearly indicates the development of multiple cracking in the FRCCs. Furthermore, the failure patterns of FRCCs under cyclic tensile loading can be qualitatively analyzed by examining the pull-out length of fibers (Figure 3) and the crack surfaces
(Figure 4) through SEM observation. In comparison to quasistatic experiments, fibers that pulled-out due to dynamic loading are approximately $91.6 \%$ longer with distinct wave-shaped textures in the axial direction, indicative of pronounced plastic deformation (Mechtcherine et al., 2011). This pronounced plastic deformation is a result of higher strain rates and higher crack opening velocities resulting in fiber-matrix debonding, destroyed fibers, and ultimately loosening of the microstructure due to pronounced micro-crack development (Müller and Mechtcherine, 2017). Moreover, several factors such as the bond strength between the fiber and the cementitious matrix, fiber aspect ratio, and matrix strength can contribute to the multiscale behavior of FRCC (Yu et al., 2018). Further investigations are necessary to fully understand the multiscale mechanical behavior of FRCC under cyclic tensile loading.

\section{Cyclic Shear Behavior of Fiber-reinforced Cementitious Materials}

Due to the incompatible material properties and the interfacial transition zone (ITZ) between fibers and cementitious matrix, the reinforcing effect mainly occurs in the post-cracking stages indicating that the pre-cracking response of FRCC is dominated by the cementitious matrix (Xu et al., 2018b). Therefore, to identify the characteristics of the cyclic shear behavior of FRCC, the focus of this review is placed on its post-cracking response. In the post-cracking stags, the cyclic shear response is highlighted by distinct constitutive behaviors: pinched hysteresis loops and accumulated volumetric plastic strain. The pinching of the strain curve (see Figure 5) is attributed to the combined effects of frictional resistance and stiffness degradation, respectively (Hung et al., 2013; Carnovale and Vecchio, 2014). This is because the inclusion of fibers not only increases the shear resistance through their dowel action and axial fiber stress (Claus, 2009) but also causes the multi-cracking behavior of the FRCC matrix. Although the multi-cracked matrix implies a stronger energy-dissipation ability and thus a higher load-carrying capacity, the generated multiple cracks inevitably cause a considerable reduction in the stiffness during the unloading process. Therefore, the stiffness degradation under cyclic shear loading contributes to a more pinched hysteresis loop (Pekoz and Pincheira, 2004; Festugato et al., 2013). However, the multiple cracks can offer a higher friction resistance for a given shear displacement, which indicates a higher energy dissipation capacity. In other words, the improved friction resistance by multiple cracks intends to increase the area of hysteresis loops and thus results in a more complex unloading/reloading behavior. It should be noted that the effectiveness of friction resistance along crack surfaces depends on the degree of crack closeness during the unloading/reloading process. For example, when stiff fibers such as steel fibers are adopted, the reinforcing fibers may prevent the cracks from closing and weakens the interface shear resistance (Toé Casagrande et al., 2006).

Another important characteristic of the cyclic shear response is the accumulation of volumetric plastic strain. For soft cementitious materials such as $\mathrm{CPB}$, shear deformation causes volume changes (especially volume contraction) and increases 


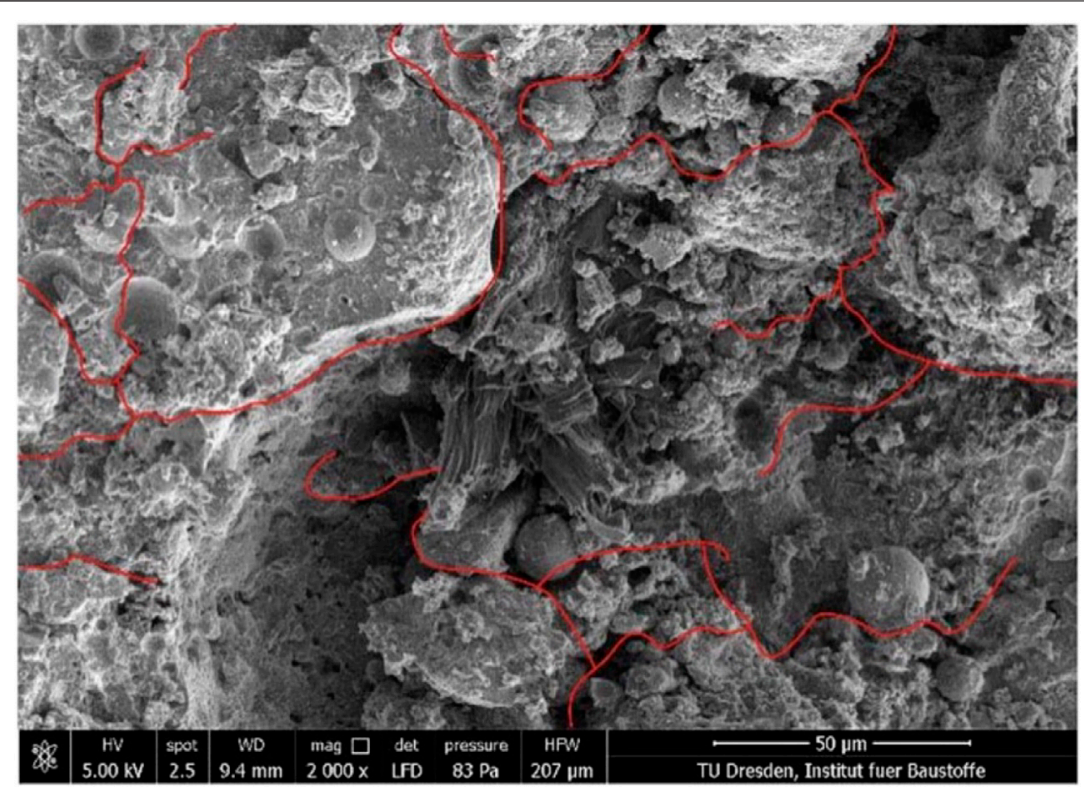

FIGURE 4 | Typical crack surfaces of FRCC under cyclic tensile loading (Müller and Mechtcherine, 2017).

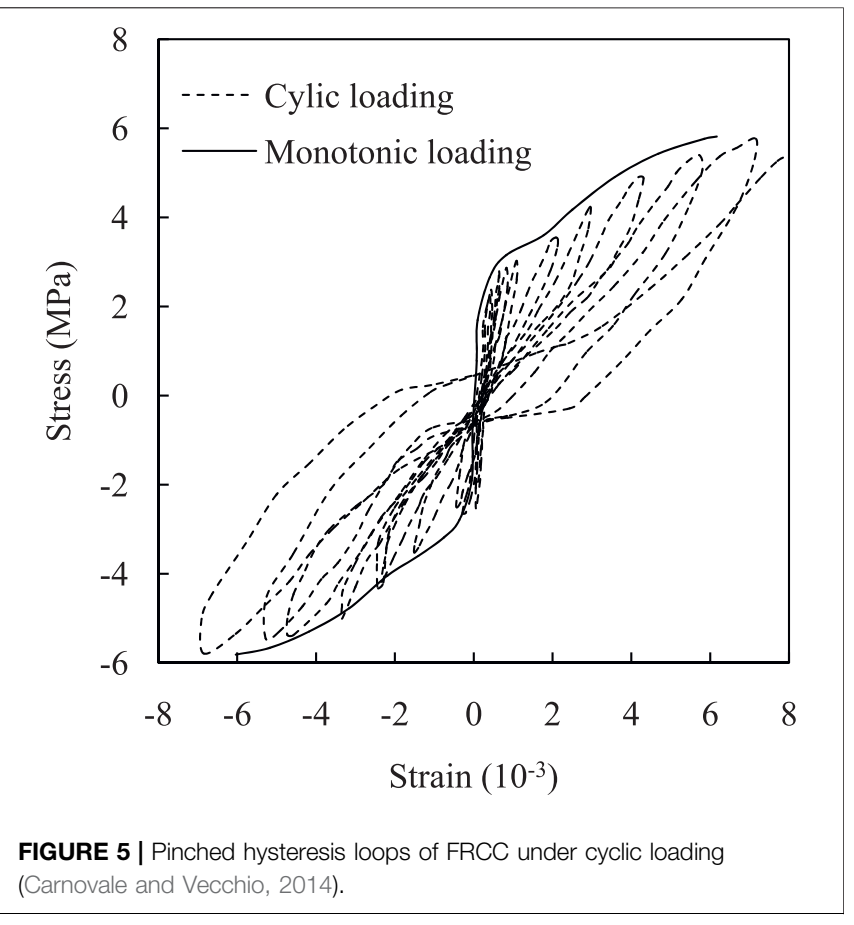

pore water pressure, which may contribute to material liquefaction (Cui and Fall, 2017a; Cui and Fall, 2020). Under cyclic shear loading, the accumulation of volumetric plastic strain occurs in the matrix. Due to the irrecoverable nature of this deformation, the matrix retains this volume change during the unloading process. Correspondingly, the accumulation of plastic strain under cyclic loading will result in the continuous development of excess PWP ( $\mathrm{Lu}$ et al., 2017). This excess
PWP causes a reduction in effective stress and material strength. In engineering applications, it is imperative to have a material with rapid dissipation of excess PWP. In this regard, it has been found that the incorporation of fibers into cementitious materials can accelerate PWP dissipation (Festugato et al., 2013). This is because 1) the inclusion of fibers induces multiple cracking responses. The resultant macro- and micro-cracks directly form the preferential seepage channels inside the matrix and thus increases the nominal hydraulic conductivity, and 2) the ITZ formed between fibers and matrix possess a larger pore size compared to those inside the matrix (Chakilam and Cui, 2020). Such larger pores can further enhance the hydraulic conductivity of FRCCs. As a result, rapid dissipation of excess PWP can be expected in soft FRCC under cyclic shear loadings, especially during the post-cracking stages. Festugato et al. (2013) studied the cyclic shear response of fiber-reinforced CPB (FR$\mathrm{CPB}$ ). Cyclic shear tests were performed on FR-CPB specimens under $50 \mathrm{kPa}$ of initial effective vertical stress and $+/-2.5 \%$ of controlled shear strain. After 1,500 cycles, the FR-CPB specimens (see Figure 6A) had an excess pore water pressure of approximately $40 \mathrm{kPa}$ and shown a $27 \%$ reduction in excess pore water pressure compared to that (approximately $55 \mathrm{kPa}$ ) of the non-reinforced specimens (see Figure 6B). Moreover, the confirmed rapid dissipation of excess PWP by the inclusion of fibers directly increases the effective stress.

For the failure patterns under cyclic shear loading, cementitious materials can exhibit significant quasi-ductile behavior when compared to the behavior of their individual components (Scrivener et al., 2004). Such macro-scale mechanical behavior can be attributed to the development of multiple micro-cracks primarily in the ITZ between cement paste and aggregate, which is often considered the weak link in cementitious materials. When fibers are introduced into the 


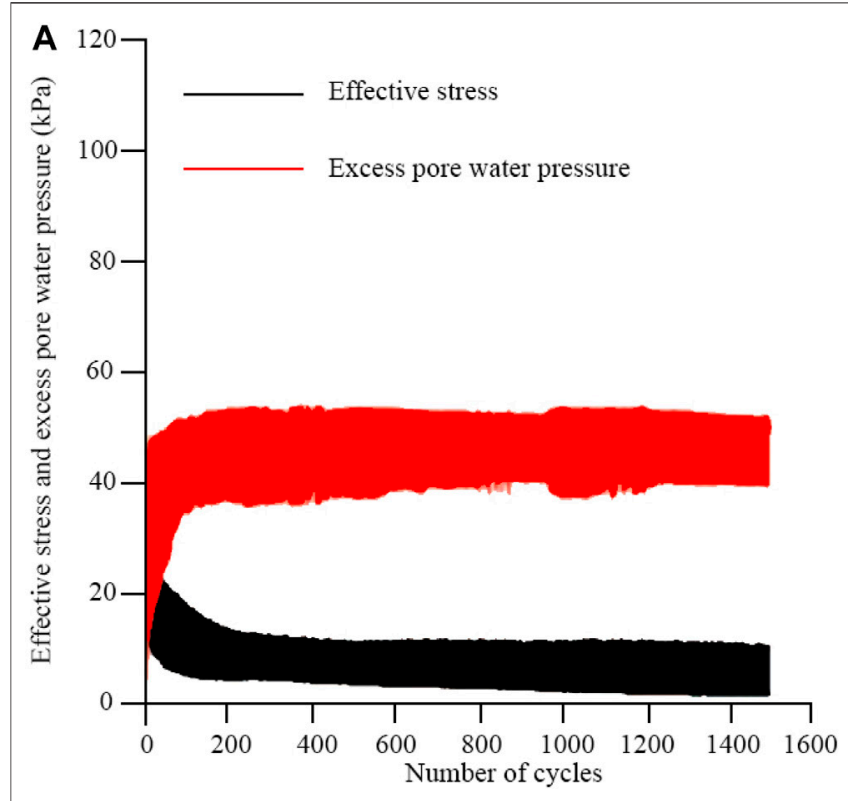

B

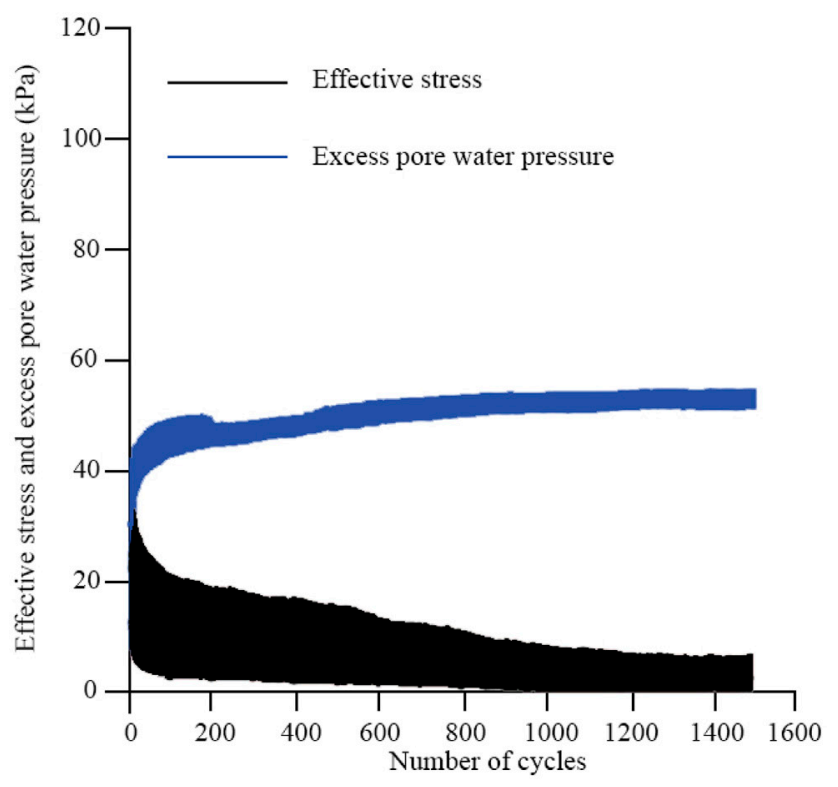

FIGURE 6 | Evolution of excess pore water pressure and effective stress in cemented paste backfill under cyclic shear loading: (A) with fiber reinforcement, and (B) without fiber reinforcement (Festugato et al., 2013).

porous matrix, a series of new ITZ between fibers and solid particles in the cementitious matrix can be generated (see Figure 7A). Similarly, the ITZ associated with the inclusion of fibers possesses strong heterogeneity and weaker fracture toughness compared with the cementitious matrix (Prokopski and Halbiniak, 2000). Consequently, when micro-cracks propagate into the new ITZ, the composite may experience crack deflection and/or branching parallel to the fibers. Furthermore, as shown in Figure $\mathbf{7 B}$, fibers can serve as a crack isolator in conjunction with the ITZ and prevent the coalescence of micro-cracks (Pupurs, 2012; Chasioti and Vecchio, 2017). Together with the stress transfer mechanism of fiber reinforcement, this crack isolator role played by the ITZ can further contribute to 1) the improvement of post-cracking stiffness and maintenance of matrix integrity (Dinh et al., 2021) and 2) multiple cracking behaviors of FRCC (Huang et al., 2021a; Li et al., 2021). Under shear loading conditions, the resultant multiple cracks cause more crack surfaces to exist in the cementitious matrix, and subsequently, more energy can be dissipated. Moreover, the inherent crack deflection and branching indicate that shear cracks can transform into tensile cracks (Pereira et al., 2011). As the cracks propagate further into the cementitious matrix, a relatively larger-scale fracture process zone (FPZ) can be formed ahead of the crack front and results in the complex nature of the cracking process in cementitious materials. More precisely, the FPZ is defined as a damage region between the intact material and the fully developed macro-crack (Otsuka and Date, 2000). Previous studies

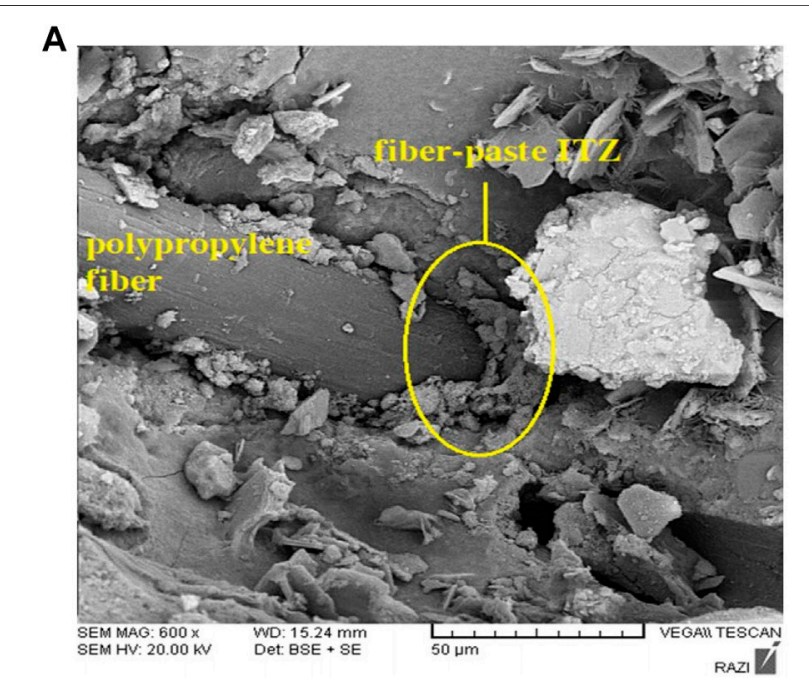

\section{B}

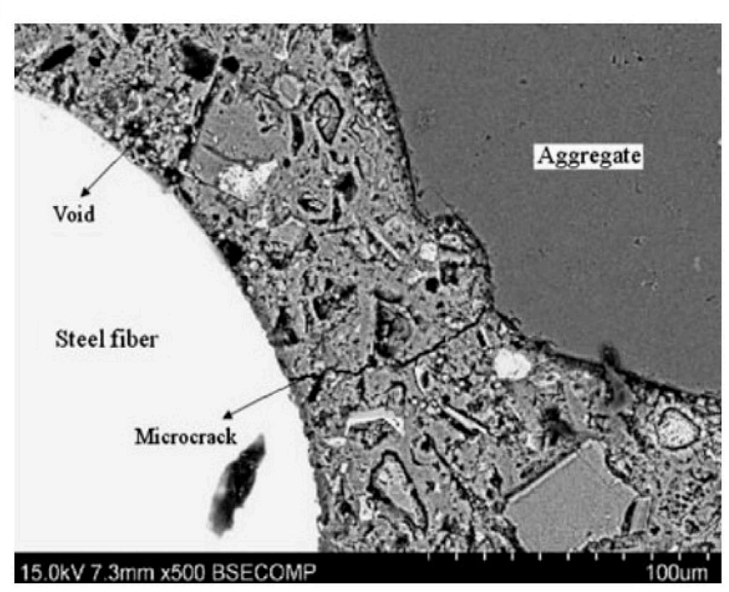

FIGURE 7 | SEM images of (A) ITZ between fiber and matrix (Behforouz et al., 2020), and (B) crack isolator role played by fiber (Wang et al., 2020). 


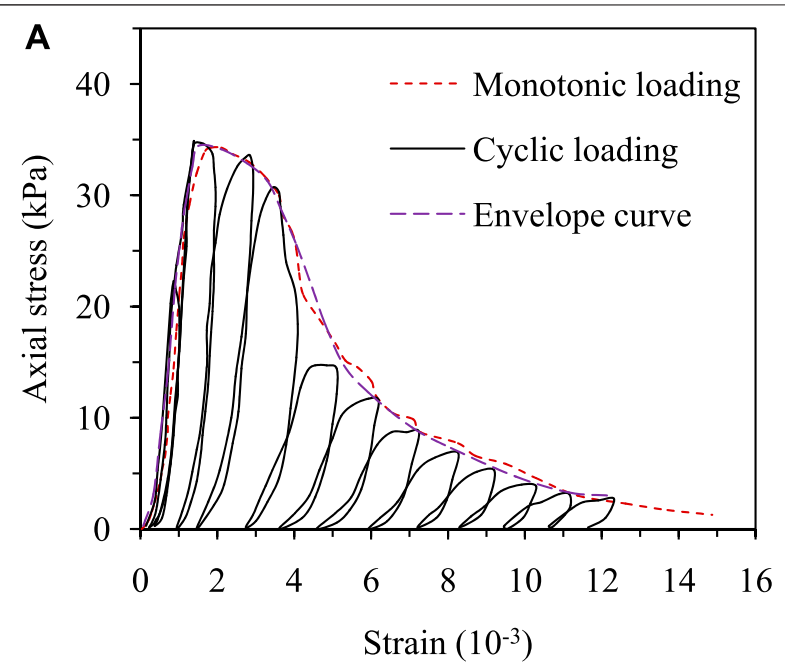

B

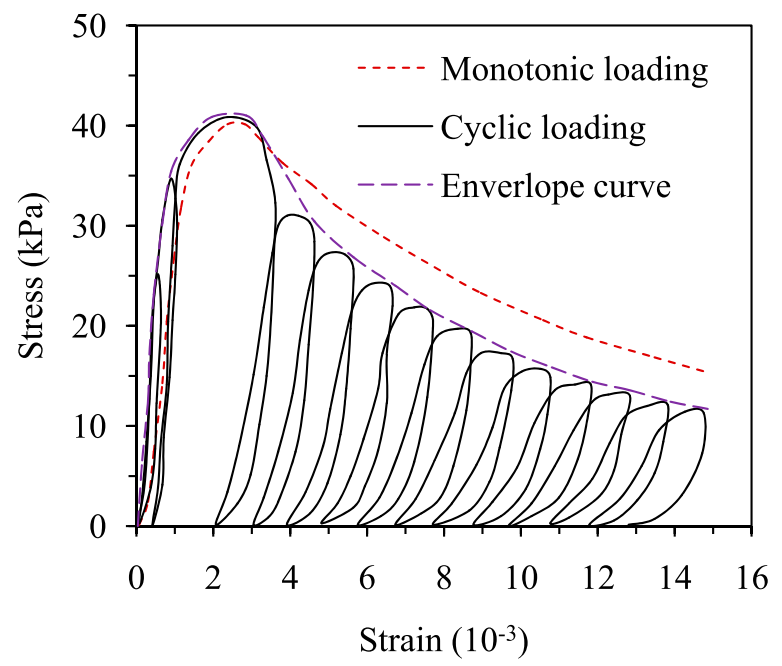

FIGURE 8 | Typical stress-strain curves of cementitious material under cyclic compressive loading: (A) without fiber reinforcement, (B) with fiber reinforcement (Li et al., 2017).

(Jankowski and Styś, 1990; Brooks, 2013) confirm that the formation of FPZ has the ability to delay crack growth and results in non-linear fracture behaviors. The FPZ of cementitious materials without fibers consists of two zones 1) zone of micro-cracks and 2) aggregate bridging zone. When fibers are introduced to the matrix, the fibers can form the additional fiber bridging zone (Park et al., 2010), which not only extends the net bridging zone but also enlarges the zone of micro-cracks through fiber-induced multiple cracking processes. As a result, the reinforced FPZ improves the fracture toughness of the FRCC. Then, under cyclic shear loading, more energy can be dissipated by this enhanced FPZ, which also confirms the role of fiber reinforcement in the post-cracking stages. In addition, the FPZ will become a crushed zone under cyclic shear loading (Erarslan, 2016). This crushed zone with loose particles and dust has two interesting implications: 1) the separation of solid particles from its original matrix requires more energy dissipation and 2) the existence of particles and dust in the crack space prevents the closure of cracks, thus, affecting the macro-scale volume change. Hence, the crack propagation in the ITZ and FPZ eventually affects the crack coalescence and thus the failure patterns at the macroscale. More specifically, the low tensile strength of plain cementitious materials implies that flexural failure plays a crucial role in the failure patterns (Liu et al., 2019). However, when fibers are introduced, the stress transfer mechanism causes a more important role played by the combined flexural and shear failure patterns. For instance, Li et al. (2019) found that the hybrid-fiber reinforced shear keys experienced concrete crushing and spalling from the specimens during tests and was accompanied by shear tension failure mode under cyclic loading. This is because the opening of flexural cracks was delayed by fiber bridging effect which leads to crack inclination and the subsequent flexure-shear failure. Similar findings were also obtained in recent publications (Choun and Park, 2015; Ying and Jin-Xin, 2018), which further highlights the effect of fiber reinforcement on the failure patterns of cementitious materials under cyclic shear loading.

\section{Cyclic Compressive Behavior of Fiber-Reinforced Cementitious Materials}

The envelope curve, usually referenced as the upper boundary of the cyclic response, can be used to analyze the constitutive behavior of FRCC under cyclic compressive loading (Xu et al., 2018a). Specifically, the deviation of the envelope stress-strain curve from the monotonic envelope could be an important mechanical characteristic of FRCC's post-peak behavior. For instance, through an experimental study on the axial cyclic compression behavior of FRCC, Li et al. (2017) found that the envelope curve consists of the ascending and the descending branches. As shown in Figure 8, the ascending branch prior to the peak stress closely traces the monotonic envelope curve. The minimal pre-peak deviation between cyclic and monotonic envelope curves was also observed from the synthetic FRCCs (Xu et al., 2018b), which further confirms the weak effect of fiber reinforcement on the pre-peak behavior under compressive loading conditions. Contrastingly, the post-peak discrepancy between cyclic and monotonic envelope curves appears when the fibers are introduced into the cementitious materials (see Figures 8A,B). The inconsistent cyclic and monotonic envelop curves in the post-peak stage can be attributed to the strengthened multiple-cracking characteristic of FRCC under cyclic compressive loading (Nataraja et al., 1999; Krahl et al., 2019). Specifically, this multiple cracking process results in significant microscale damage accumulation and macroscale stress deterioration ( $\mathrm{Li}$ et al., 2017; Xu et al., 2018a). Consequently, fiber reinforcement is able to yield different damage and post-peak (softening or hardening) mechanisms responsible for the macroscale mechanical response under monotonic and/or cyclic loadings (Krahl et al., 2019). Secondly, it has also been found that the increased loading cycles result in a more defined hysteresis loop in FRCC, which indicates an improved hysteretic energy dissipation capability. In 
contrast, plain cementitious composites are featured with narrow hysteresis loops under cyclic compressive loading (Deng and Zhang, 2017) and several major cracks from the beginning of loading till specimen failure (Yu et al., 2020). This is because the formation of fiber bridging zone in the vicinity of crack front extends FPZ and the resultant stress transfer causes multiple cracking in the matrix (Li et al., 2017; Yu et al., 2020). More precisely, the prerequisite for the effectiveness of fiber reinforcement is the development of locally matched stress levels between fibers and adjacent cementitious matrix (Abbas and Iqbal Khan, 2016; Mohonee and Goh, 2016). However, distinct mechanical properties between fiber and granular materials may cause the unmatched stress levels when the deformation of fiber drops to a certain value and thus fade the local fiber reinforcement effect (Libos and Cui, 2021). In other words, the cyclic loading and unloading processes will repeatedly reactivate and deactivate the fiber reinforcement at the cost of damage accumulation in the cementitious matrix. Consequently, strengthened stress transfer through combined fiber and aggregate bridging zones into the cementitious matrix is able to endow the materials with significantly improved mechanical performance including the higher hysteretic energy dissipation capacity.

In addition to the stress-strain response, the macroscale volume change of FRCC can also demonstrate different characteristics when subjected to cyclic compressive loading. The macroscale volume change is intimately related to the crack opening and closing during the loading and unloading processes (Alkan et al., 2007). As previously discussed, fibers embedded into the matrix may act as crack arresters and cause crack branching and deflection. Consequently, both tensile and shear cracks are able to propagate inside the cementitious composite and promote multiple cracking behaviors. The effect of tensile crack on volume change is straightforward, i.e., the opening and closing of tensile cracks can directly cause the local volume expansion and contraction. However, the volume change associated with shear cracks is dependent on cementation extent (Amini et al., 2014). To maintain the shear crack growth, the debonding process accompanied by the particle sliding and rotation along the rough crack surfaces are required (Wang et al., 2021a). Therefore, similar to the overconsolidated soils, a larger local volume expansion can be expected along the shear cracks when FRCCs are prepared with higher cement content (Jiang et al., 2011). Conversely, soft cementitious materials with lower cement content such as FR-CPB possess weak bond strength. As a result, the shearing process along crack surfaces can cause the debonding processes to a larger regime in the vicinity of crack surfaces and promote particle re-packing to a higher extent, which in turn weakens the sliding and rotation of particles along the crack surfaces. Consequently, the locally depressed volume expansion can be expected in soft cementitious materials (Cui and Fall, 2016a). Additionally, the introduction of fibers indirectly contributes to the confinement of the cementitious composite (Ramesh et al., 2003). This is because fiber bridging capacity is able to provide passive confinement to the damaged matrix (Zhou et al., 2015) and thus further limit the volume change at a given stress level.

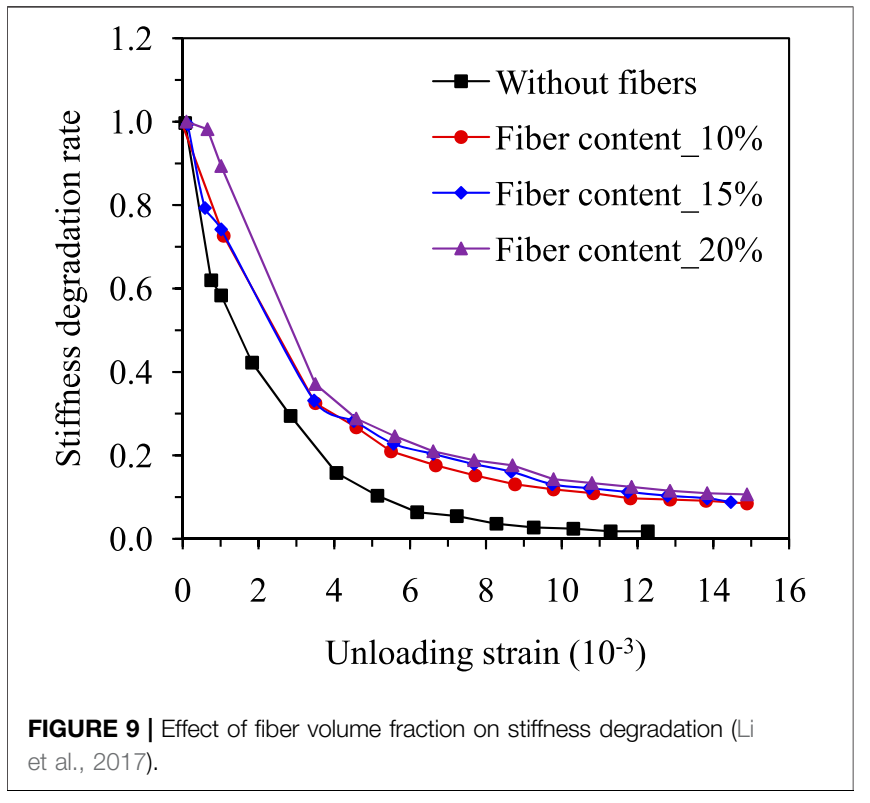

In terms of mechanical properties of FRCCs under cyclic compressive loading, the elastic modulus, compressive strength, the energy dissipation capacity and Poisson's ratio can be extracted from the macroscale stress-strain behaviors and used to evaluate the engineering performance of FRCCs. Specifically, the evolution of elastic modulus can be used as a valuable indicator for the damage accumulation inside cementitious materials. When materials are cyclically loaded, the material stiffness degrades due to crack propagation. However, it has been confirmed that the addition of fibers into the cementitious matrix is able to effectively alleviate the degradation rate of elastic stiffness (see Figure 9) (Yu et al., 2020) and improve the ductile response of cementitious material at the macroscale (Siva and Pankaj, 2019). With regards to composite strength, the effect of fibers is less significant, and some studies (Banthia and Gupta, 2004; Tahenni et al., 2016) even found a negative effect of fibers on the compressive strength of FRCCs. As previously discussed, fibers are most effective when their tensile strength is mobilized through their bridging capacity across tensile cracks. However, under compressive loading fibers may initiate matrix crushing through local stress concentration and induce defects in the cementitious matrix as a result of inadequate compactness (Boulekbache et al., 2010; Boulekbache et al., 2012), which may adversely affect the compressive strength of FRCC. However, the fiber reinforcement technique is able to act as a positive contributor to the compressive strength when a multiscale reinforcement approach is adopted. The critical discussion on the potential usage of the multiscale reinforcement technique will be presented in Discussion on the Multiscale Reinforcement Technique. Furthermore, the hysteresis loops in Figure 8 suggest the inclusion of fibers significantly improves the hysteretic energy dissipation in FRCCs ( $\mathrm{Li}$ et al., 2017; Xu et al., 2018a). When FRCCs are cyclically loaded, the reinforcement mechanisms including fiber bridging, fiber sliding, fiber pull-out, and fiber-matrix debonding are responsible for the 


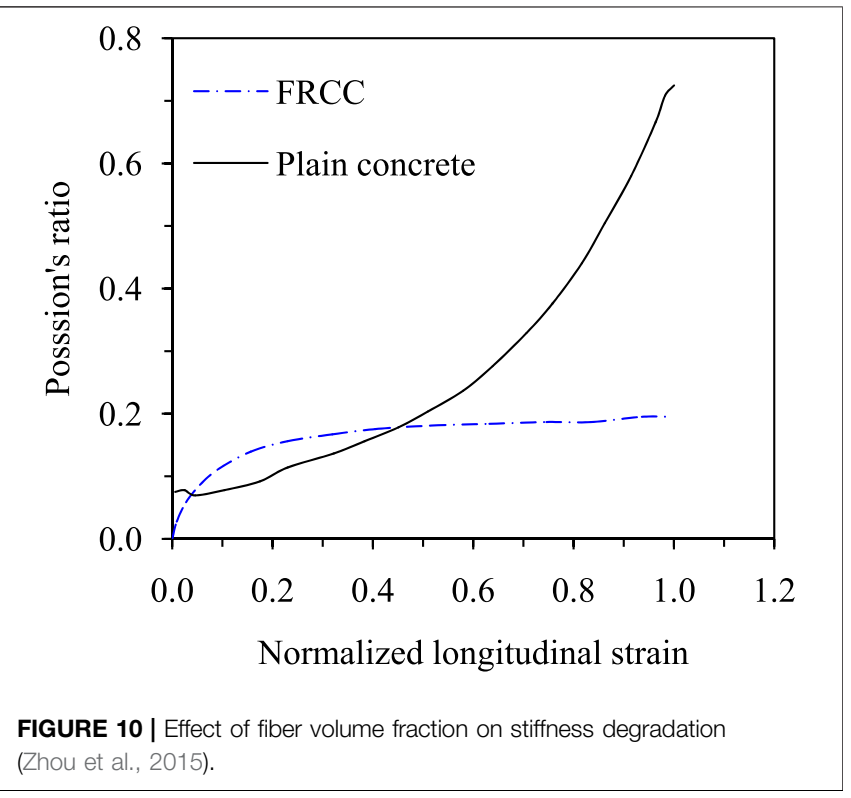

formation of energy dissipation capacity (Trainor et al., 2013). Correspondingly, the absence of these mechanisms in plain cementitious materials inevitably results in smaller hysteretic loops and subsequent low energy dissipation capacity, because the coalescence of microcracks into macrocracks is the only avenue for energy dissipation in plain cementitious materials. Lastly, Zhou et al. (2015) have identified that the cracking process significantly influences the evolution of Poisson's ratio. As illustrated in Figure 10, Poisson's ratio of plain cementitious materials increases exponentially with axial strain due to progressive micro-cracking in the cementitious matrix. However, when the fiber reinforcement is introduced into the cementitious materials, the Poisson's ratio shows a logarithmic relationship to the axial strain and such observation clearly confirms the fiber's crack-bridging capacity is also able to restrict further crack opening in the lateral direction and thus affects the macroscale volume change.

For the failure patterns of FRCCs under compressive loading, the plain cementitious composites are dominated by tensile cracks parallel to the loading direction (Xu et al., 2018a). With the introduction of fibers into the matrix, the failure mode is transformed into a more ductile shear failure (Yu et al., 2020). For instance, through CT scan technology, Mínguez et al. (2019) reconstruct crack propagation inside the cementitious matrix under cyclic compressive loadings. The obtained CT images (Figure 11) clearly show the crack branching and deflection inside the FRCCs. Such cracking process inside the matrix can be attributed to multiple mechanisms including 1) exceedance of the tensile strength of the matrix, 2) debonding between fibers and matrix, and 3 ) debonding between aggregates and matrix ( $\mathrm{Li}$ et al., 2017). More specifically, due to the relatively weak tensile strength, the tensile microcracks can be developed in the matrix under cyclic compressive loadings. However, due to the development of FPZ in the vicinity of crack surfaces, the initial tensile microcracks are restrained and/or deflected by the fibers, limiting crack growth and thus restricting volume changes in the cementitious matrix (Li et al., 2017; Xu et al., 2018a; Siva and Pankaj, 2019). In other words, these fibers act as crack barriers, resulting in a more curved and inclined cracking path as the load increases (Yun et al., 2007; Li et al., 2017). The microscale crack deflection and possible branching in the vulnerable regions such as ITZ can further complicate the local stress state including shear stress concentration and associated shear crack propagation (Huang et al., 2018). Consequently, FRCCs may exhibit both macroscale tensile and shear cracks under cyclic compressive loadings.

\section{DISCUSSION ON THE MULTISCALE REINFORCEMENT TECHNIQUE}

Based on the comprehensive review on constitutive behavior, mechanical properties, and failure patterns of FRCC, it can be found the effect of fiber reinforcement mainly appears in the postpeak stage. However, the role played by fibers in the pre-peak region is not well understood. For instance, the present studies on the fiber reinforcement technique indicate the usage of only one type of fiber has a very limited effect on the pre-peak behavior of

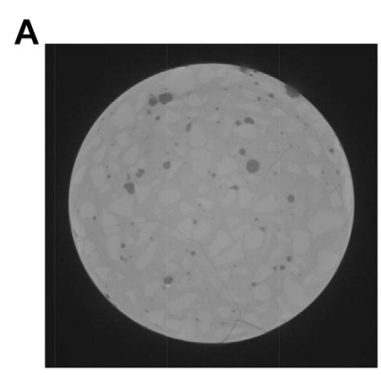

B

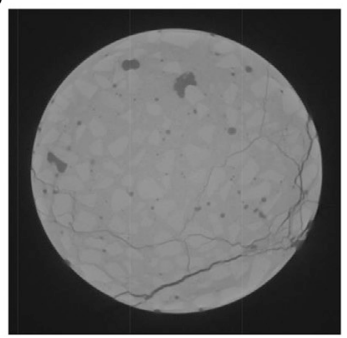

C

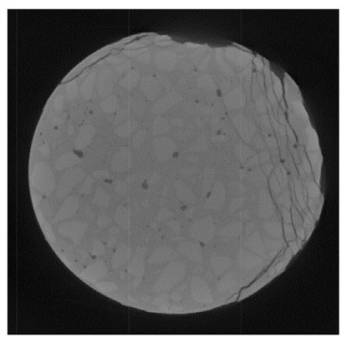

FIGURE 11 | CT images of cracking process in FRCC under cyclic compressive loading: (A) 0 cycles, (B) 20,000 cycles, and (C) 2,000,000 cycles (Mínguez et al., 2019). 
FRCC. Since the effectiveness of fiber reinforcement at the prepeak stage is closely associated with the improvement of peak stress (i.e., material strength), more studies are required to explore the mechanisms behind the pre-peak reinforcement techniques. In this regard, it has been confirmed that cracks within cementitious composites exist in multiscale dimensions. Therefore, the synergistic use of fibers with different geometrical and mechanical properties in cementitious composites is often motivated by the multiscale nature of the cracking processes in FRCC. For example, recent studies (Masud and Chorzepa, 2016; Alshaghel et al., 2018; Pan et al., 2018) suggests that a multiscale reinforcement approach is able to form a hierarchically reinforced cementitious matrix and effectively improve the dynamic response of FRCC, especially its prepeak behavior. This is because crack initiation is abated at the nanoscale level by employing nanofibers, and crack growth is delayed at micro and macro levels respectively by incorporating micro and macro fibers (Pereira et al., 2012). Therefore, the multiscale reinforcement techniques have the potentials to significantly improve the integrity and stability of FRCC at the field scale. However, due to the discrete nature of artificial fibers (including nanoparticles and micro- and macro-fibers), the multiscale reinforcement approach cannot form a continuous reinforcement network in the porous matrix. Consequently, the locally unreinforced zones always exist in FRCC and thus create the preferential regimes for crack propagation. Therefore, more studies are urgently required to overcome such structural and functional defects associated with fiber reinforcement technique, especially for soft cementitious materials under extreme loading conditions.

\section{CONCLUSION}

This literature review presents a comprehensive overview of start-of-the-art research on the FRCC under cyclic loading conditions. The macroscale constitutive behavior and the associated mechanical properties, and microscale cracking processes under cyclic tensile, shear, and compressive loading conditions are summarized in-depth. Based on the

\section{REFERENCES}

Abbas, Y. M., and Iqbal Khan, M. (2016). Fiber-Matrix Interactions in FiberReinforced Concrete: A Review. Arab J Sci Eng 41, 1183-1198. doi:10.1007/ s13369-016-2099-1

Aggelis, D. G. (2011). Classification of Cracking Mode in Concrete by Acoustic Emission Parameters. Mechanics Research Communications 38, 153-157. doi:10.1016/j.mechrescom.2011.03.007

Aggelis, D. G., Soulioti, D. V., Sapouridis, N., Barkoula, N. M., Paipetis, A. S., and Matikas, T. E. (2011). Acoustic Emission Characterization of the Fracture Process in Fibre Reinforced Concrete. Construction and Building Materials 25, 4126-4131. doi:10.1016/j.conbuildmat.2011.04.049

Alkan, H., Cinar, Y., and Pusch, G. (2007). Rock Salt Dilatancy Boundary from Combined Acoustic Emission and Triaxial Compression Tests. International Journal of Rock Mechanics and Mining Sciences 44, 108-119. doi:10.1016/ j.ijrmms.2006.05.003 study findings in the present literature, the following conclusions can be drawn:

1) For the macroscale constitutive behavior, the fiber reinforcement mainly improves the post-cracking behavior, especially in the post-peak stage. Correspondingly, the enhancement of material stiffness, hysteretic energy dissipation capacity, and ductility has been observed from FRCC under cyclic tensile, shear, and compressive loadings.

2) The crack opening and closing at the microscale govern the macroscale volume change under cyclic tensile loadings. In contrast, the shear-induced volume change is dominated by the particle repackaging along the shear cracks.

3) The inclusion of fibers is able to enlarge the pore size of ITZ and accelerate dissipation of the excess PWP under cyclic loading. Therefore, rapid changes in effective stress and the mechanical properties are expected in the soft cementitious materials such as CPB.

4) For the microscale crack propagation under cyclic loadings, introducing fibers into the cementitious matrix extends the FPZ and causes complex cracking processes such as crack deflection and branching. Consequently, the FRCC commonly demonstrates both tensile and shear cracks under cyclic loadings.

5) Based on the multiscale geomechanical behavior of FRCC, the multiscale reinforcement technique can be considered a promising approach to restrict cracking at different length scales inside the cementitious matrix under cyclic loadings.

\section{AUTHOR CONTRIBUTIONS}

LC conceived the original ideas and supervised this study. JM carried out the comprehensive review and wrote this article.

\section{FUNDING}

This work was funded by Natural Sciences and Engineering Research Council of Canada (NSERC), and also funded by the State Key Laboratory of Geohazard Prevention and Geoenvironment Protection Open Fund (SKLGP2021K004).

Alshaghel, A., Parveen, S., Rana, S., and Fangueiro, R. (2018). Effect of Multiscale Reinforcement on the Mechanical Properties and Microstructure of Microcrystalline Cellulose-Carbon Nanotube Reinforced Cementitious Composites. Composites Part B: Engineering 149, 122-134. doi:10.1016/ j.compositesb.2018.05.024

Amini, Y., Hamidi, A., and Asghari, E. (2014). Shear strength-dilation characteristics of cemented sand-gravel mixtures. International Journal of Geotechnical Engineering 8, 406-413. doi:10.1179/ 1939787913 y.0000000026

Banthia, N., and Gupta, R. (2004). Hybrid Fiber Reinforced Concrete (Hyfrc): Fiber Synergy in High Strength Matrices. Mat. Struct. 37, 707-716. doi:10.1007/ bf02480516

Bernard, E. S. (2015). Age-Dependent Changes in Post-Crack Performance of Fibre Reinforced Shotcrete Linings. Tunnelling and Underground Space Technology 49, 241-248. doi:10.1016/j.tust.2015.05.006

Boulekbache, B., Hamrat, M., Chemrouk, M., and Amziane, S. (2010). Flowability of Fibre-Reinforced Concrete and Its Effect on the Mechanical Properties of the 
Material. Construction and Building Materials 24, 1664-1671. doi:10.1016/ j.conbuildmat.2010.02.025

Boulekbache, B., Hamrat, M., Chemrouk, M., and Amziane, S. (2012). Influence of Yield Stress and Compressive Strength on Direct Shear Behaviour of Steel Fibre-Reinforced Concrete. Construction and Building Materials 27, 6-14. doi:10.1016/j.conbuildmat.2011.07.015

Boulekbache, B., Hamrat, M., Chemrouk, M., and Amziane, S. (2016). Flexural Behaviour of Steel Fibre-Reinforced Concrete under Cyclic Loading. Construction and Building Materials 126, 253-262. doi:10.1016/ j.conbuildmat.2016.09.035

Brooks, Z (2013). Fracture Process Zone: Microstructure and Nanomechanics in Quasi-Brittle Materials PhD thesis. Massachusetts Institute of Technology.

Cao, S., Yilmaz, E., and Song, W. (2019). Fiber Type Effect on Strength, Toughness and Microstructure of Early Age Cemented Tailings Backfill. Construction and Building Materials 223, 44-54. doi:10.1016/j.conbuildmat.2019.06.221

Cao, S., Yilmaz, E., Yin, Z., Xue, G., Song, W., and Sun, L. (2021). Ct Scanning of Internal Crack Mechanism and Strength Behavior of Cement-Fiber-Tailings Matrix Composites. Cement and Concrete Composites 116, 103865. doi:10.1016/ j.cemconcomp.2020.103865

Cao, S., Zheng, D., Yilmaz, E., Yin, Z., Xue, G., and Yang, F. (2020). Strength Development and Microstructure Characteristics of Artificial Concrete Pillar Considering Fiber Type and Content Effects. Construction and Building Materials 256, 119408. doi:10.1016/j.conbuildmat.2020.119408

Carnovale, D., and Vecchio, F.J. (2014). Effect of Fiber Material and Loading History on Shear Behavior of Fiber-Reinforced Concrete. ACI Structural Journal 111, 1235-1244.

Caverzan, A., Cadoni, E., and Di Prisco, M. (2012). Tensile Behaviour of High Performance Fibre-Reinforced Cementitious Composites at High Strain Rates. International Journal of Impact Engineering 45, 28-38. doi:10.1016/ j.ijimpeng.2012.01.006

Chakilam, S., and Cui, L. (2020). Effect of Polypropylene Fiber Content and Fiber Length on the Saturated Hydraulic Conductivity of Hydrating Cemented Paste Backfill. Construction and Building Materials 262, 120854. doi:10.1016/ j.conbuildmat.2020.120854

Chasioti, S.G., and Vecchio, F.J. (2017). Shear Behavior and Crack Control Characteristics of Hybrid Steel Fiber-Reinforced Concrete Panels. ACI Structural Journal 114, 209. doi:10.14359/51689164

Chen, X., Shi, X., Zhou, J., and Yu, Z. (2019). Influence of Polypropylene Fiber Reinforcement on Tensile Behavior and Failure Mode of Tailings Cemented Paste Backfill. IEEE Access 7, 69015-69026. doi:10.1109/ access.2019.2919480

Choun, Y.-S., and Park, J. (2015). Evaluation of Seismic Shear Capacity of Prestressed Concrete Containment Vessels with Fiber Reinforcement. Nuclear Engineering and Technology 47, 756-765. doi:10.1016/j.net.2015.06.006

Chung, J.-H., Son, D.-H., Kim, S.-Y., Bae, B.-I., and Choi, C.-S. (2021). Hysteretic Behavior of Reinforced Concrete Coupling Beams According to Volume Fraction of Steel Fiber. Sustainability 13, 182. doi:10.3390/su13010182

Claus, T (2009). Non-Linear Finite Element Analysis of Shear Critical Reinforced Concrete BeamsMaster's degree. Delft University of Technology.

Cui, L., and Fall, M. (2015). A coupled thermo-hydro-mechanical-chemical model for underground cemented tailings backfill. Tunnelling and Underground Space Technology 50, 396-414. doi:10.1016/j.tust.2015.08.014

Cui, L., and Fall, M. (2016a). An Evolutive Elasto-Plastic Model for Cemented Paste Backfill. Computers and Geotechnics 71, 19-29. doi:10.1016/ j.compgeo.2015.08.013

Cui, L., and Fall, M. (2016b). Multiphysics Model for Consolidation Behavior of Cemented Paste Backfill. International Journal of Geomechanics 17, 04016077.

Cui, L., and Fall, M. (2017a). Modeling of Pressure on Retaining Structures for Underground Fill Mass. Tunnelling and Underground Space Technology 69, 94-107. doi:10.1016/j.tust.2017.06.010

Cui, L., and Fall, M. (2017b). Multiphysics Modeling of Arching Effects in Fill Mass. Computers and Geotechnics 83, 114-131. doi:10.1016/j.compgeo.2016.10.021

Cui, L., and Fall, M. (2018). Multiphysics Modeling and Simulation of Strength Development and Distribution in Cemented Tailings Backfill Structures. Int J Concr Struct Mater 12, 25. doi:10.1186/s40069-018-0250-y

Cui, L., and Fall, M. (2019). Mathematical Modelling of Cemented Tailings Backfill: A Review. International Journal of Mining, Reclamation and Environment 33, 389-408. doi:10.1080/17480930.2018.1453320
Cui, L., and Fall, M. (2020). Numerical Simulation of Consolidation Behavior of Large Hydrating Fill Mass. International Journal of Concrete Structures and Materials 14, 1-16. doi:10.1186/s40069-020-0398-0

Deng, M., and Zhang, Y. (2017). Cyclic Loading Tests of Rc Columns Strengthened with High Ductile Fiber Reinforced Concrete Jacket. Construction and Building Materials 153, 986-995. doi:10.1016/j.conbuildmat.2017.07.175

Dinh, N. H., Park, S.-H., and Choi, K.-K. (2021). Effect of Dispersed Micro-Fibers on Tensile Behavior of Uncoated Carbon Textile-Reinforced Cementitious Mortar after High-Temperature Exposure. Cement and Concrete Composites 118, 103949. doi:10.1016/j.cemconcomp.2021.103949

Dönmez, D., Dönmez, A. A., and Gençoğlu, M. (2020). Mechanical Response of Textile Reinforced Cementitious Composite Tubes under Monotonic and Cyclic Loadings. Construction and Building Materials 251, 118963. doi:10.1016/j.conbuildmat.2020.118963

Erarslan, N. (2016). Microstructural Investigation of Subcritical Crack Propagation and Fracture Process Zone (Fpz) by the Reduction of Rock Fracture Toughness under Cyclic Loading. Engineering Geology 208, 181-190. doi:10.1016/ j.enggeo.2016.04.035

Festugato, L., Fourie, A., and Consoli, N. C. (2013). Cyclic Shear Response of FibreReinforced Cemented Paste Backfill. Géotechnique Letters 3, 5-12. doi:10.1680/ geolett.12.00042

Guo, M., Zhong, Q., Zhou, Y., Hu, B., Huang, Z., and Yue, Y. (2020). Influence of Flexural Loading and Chloride Exposure on the Fatigue Behavior of High-Performance Lightweight Engineered Cementitious Composites. Construction and Building Materials 249, 118512. doi:10.1016/ j.conbuildmat.2020.118512

Hu, J.-H., Sun, M.-Q., Li, J., and Wang, Y.-J. (2018). Mechanical Performances and Evolution of Stiffness of Thin-Walled Strain Hardening Cement-Based Composites Pipes During Cyclic Loading. Construction and Building Materials 184, 400-407. doi:10.1016/j.conbuildmat.2018.07.001

Huang, B.-T., Li, Q.-H., Xu, S.-L., Liu, W., and Wang, H.-T. (2018). Fatigue Deformation Behavior and Fiber Failure Mechanism of Ultra-High Toughness Cementitious Composites in Compression. Materials \& Design 157, 457-468. doi:10.1016/j.matdes.2018.08.002

Huang, B.-T., Weng, K.-F., Zhu, J.-X., Xiang, Y., Dai, J.-G., and Li, V. C. (2021a). Engineered/Strain-Hardening Cementitious Composites (Ecc/Shcc) with an Ultra-High Compressive Strength over 210 mpa. Composites Communications 26, 100775. doi:10.1016/j.coco.2021.100775

Huang, Z., Cao, S., and Yilmaz, E. (2021b). Investigation on the Flexural Strength, Failure Pattern and Microstructural Characteristics of Combined Fibers Reinforced Cemented Tailings Backfill. Construction and Building Materials 300, 124005. doi:10.1016/j.conbuildmat.2021.124005

Hung, C.-C., Su, Y.-F., and Yu, K.-H. (2013). Modeling the Shear Hysteretic Response for High Performance Fiber Reinforced Cementitious Composites. Construction and Building Materials 41, 37-48. doi:10.1016/ j.conbuildmat.2012.12.010

Jankowski, L. J., and Styś, D. J. (1990). Formation of the Fracture Process Zone in Concrete. Engineering Fracture Mechanics 36, 245-253. doi:10.1016/00137944(90)90005-2

Jiang, M. J., Yan, H. B., Zhu, H. H., and Utili, S. (2011). Modeling Shear Behavior and Strain Localization in Cemented Sands by Two-Dimensional Distinct Element Method Analyses. Computers and Geotechnics 38, 14-29. doi:10.1016/j.compgeo.2010.09.001

Jun, P., and Mechtcherine, V. (2010). Behaviour of Strain-hardening Cementbased Composites (SHCC) under monotonic and cyclic tensile loading. Cement and Concrete Composites 32, 801-809. doi:10.1016/j.cemconcomp.2010.07.019

Khlef, F. L., Barbosa, A. R., and Ideker, J. H. (2019). Tension and Cyclic Behavior of High-Performance Fiber-Reinforced Cementitious Composites. J. Mater. Civ. Eng. 31, 04019220. doi:10.1061/(asce)mt.1943-5533.0002844

Krahl, P. A., Gidrão, G. d. M. S., and Carrazedo, R. (2019). Cyclic Behavior of Uhpfrc under Compression. Cement and Concrete Composites 104, 103363. doi:10.1016/j.cemconcomp.2019.103363

Külekçi, G. (2021). Comparison of Field and Laboratory Result of Fiber Reinforced Shotcrete Application. Periodica Polytechnica Civil Engineering 65, 463-473. doi:10.3311/ppci.17033

Li, B., Chi, Y., Xu, L., Li, C., and Shi, Y. (2018a). Cyclic Tensile Behavior of Sfrc: Experimental Research and Analytical Model. Construction and Building Materials 190, 1236-1250. doi:10.1016/j.conbuildmat.2018.09.140 
Li, B., Chi, Y., Xu, L., Shi, Y., and Li, C. (2018b). Experimental Investigation on the Flexural Behavior of Steel-Polypropylene Hybrid Fiber Reinforced Concrete. Construction and Building Materials 191, 80-94. doi:10.1016/ j.conbuildmat.2018.09.202

Li, B., Xu, L., Chi, Y., Huang, B., and Li, C. (2017). Experimental Investigation on the Stress-Strain Behavior of Steel Fiber Reinforced Concrete Subjected to Uniaxial Cyclic Compression. Construction and Building Materials 140, 109-118. doi:10.1016/j.conbuildmat.2017.02.094

Li, Q.-H., Yin, X., Huang, B.-T., Luo, A.-M., Lyu, Y., Sun, C.-J., and Xu, S.-L. (2021). Shear Interfacial Fracture of Strain-Hardening Fiber-Reinforced Cementitious Composites and Concrete: A Novel Approach. Engineering Fracture Mechanics 253, 107849. doi:10.1016/j.engfracmech.2021.107849

Li, Z.-X., Li, C.-H., and Yan, J.-B. (2019). Seismic Behaviour of HybridFibre Reinforced Concrete Shear Keys in Immersed Tunnels. Tunnelling and Underground Space Technology 88, 16-28. doi:10.1016/ j.tust.2019.02.022

Libos, I.L.S., and Cui, L. (2020). "Mechanical Properties and Behavior of Early-Age Fiber-Reinforced Cemented Paste Backfill," in Proceedings of the 5rd International Conference on Civil Structural and Transportation Engineering (Virtual Conference: Avestia).

Libos, I.L.S., and Cui, L. (2021). "Time- and Temperature-Dependence of Compressive and Tensile Behaviors of Polypropylene Fiber-Reinforced Cemented Paste Backfill," in Frontiers of Structural and Civil Engineering. (in presss).

Lin, J.-X., Song, Y., Xie, Z.-H., Guo, Y.-C., Yuan, B., Zeng, J.-J., and Wei, X. (2020). Static and Dynamic Mechanical Behavior of Engineered Cementitious Composites with Pp and Pva Fibers. Journal of Building Engineering 29, 101097. doi:10.1016/j.jobe.2019.101097

Liu, N., Cui, L., and Wang, Y. (2020). Analytical Assessment of Internal Stress in Cemented Paste Backfill. Advances in Materials Science and Engineering 2020, 6666548. doi:10.1155/2020/6666548

Liu, X., Wu, T., and Liu, Y. (2019). Stress-Strain Relationship for Plain and FibreReinforced Lightweight Aggregate Concrete. Construction and Building Materials 225, 256-272. doi:10.1016/j.conbuildmat.2019.07.135

Lu, G., Fall, M., and Cui, L. (2017). A Multiphysics-Viscoplastic Cap Model for Simulating Blast Response of Cemented Tailings Backfill. Journal of Rock Mechanics and Geotechnical Engineering 9, 551-564. doi:10.1016/ j.jrmge.2017.03.005

Ma, G., Li, Z., Yi, X., and Guo, L. (2016). Macro-Meso Experiment of FiberReinforced Cement Paste Filling Material. Journal of Beijing University of Technology 42, 406-412.

Masud, M., and Chorzepa, M. G. (2016). Impact Resilience of Multiscale Fibre Reinforced Composites. Magazine of Concrete Research 68, 379-390. doi:10.1680/jmacr.15.00184

Mechtcherine, V., Millon, O., Butler, M., and Thoma, K. (2011). Mechanical Behaviour of Strain Hardening Cement-Based Composites under Impact Loading. Cement and Concrete Composites 33, 1-11. doi:10.1016/ j.cemconcomp.2010.09.018

Mínguez, J., Gutiérrez, L., González, D. C., and Vicente, M. A. (2019). Plain and Fiber-Reinforced Concrete Subjected to Cyclic Compressive Loading: Study of the Mechanical Response and Correlations with Microstructure Using Ct Scanning. Applied Sciences 9, 3030. doi:10.3390/app9153030

Mohonee, V. K., and Goh, K. L. (2016). Effects of fibre-fibre interaction on stress uptake in discontinuous fibre reinforced composites. Composites Part B: Engineering 86, 221-228. doi:10.1016/j.compositesb.2015.10.015

Müller, S., and Mechtcherine, V. (2017). Fatigue Behaviour of Strain-Hardening Cement-Based Composites (Shcc). Cement and Concrete Research 92, 75-83. doi:10.1016/j.cemconres.2016.11.003

Nataraja, M. C., Dhang, N., and Gupta, A. P. (1999). Stress-strain curves for steelfiber reinforced concrete under compression. Cement and Concrete Composites 21, 383-390. doi:10.1016/s0958-9465(99)00021-9

Otsuka, K., and Date, H. (2000). Fracture Process Zone in Concrete Tension Specimen. Engineering Fracture Mechanics 65, 111-131. doi:10.1016/s00137944(99)00111-3

Pakravan, H. R., and Ozbakkaloglu, T. (2019). Synthetic Fibers for Cementitious Composites: A Critical and in-Depth Review of Recent Advances. Construction and Building Materials 207, 491-518. doi:10.1016/ j.conbuildmat.2019.02.078
Pan, J., Cai, J., Ma, H., and Leung, C. K. Y. (2018). Development of Multiscale Fiber-Reinforced Engineered Cementitious Composites with PVA Fiber and CaCO3 Whisker. J. Mater. Civ. Eng. 30, 04018106. doi:10.1061/(asce)mt.19435533.0002305

Park, K., Paulino, G. H., and Roesler, J. (2010). Cohesive Fracture Model for Functionally Graded Fiber Reinforced Concrete. Cement and Concrete Research 40, 956-965. doi:10.1016/j.cemconres.2010.02.004

Pekoz, H.A., and Pincheira, J.A. (2004). "Seismic Response of Strength and Stiffness Degrading Single Degree of Freedom Systems," in 13th World Conference on Earthqauke Engineering, Canada (Vancouver, B.C.).

Pereira, E., Fischer, G., and Barros, J.A. (2011). "Image-Based Detection and Analysis of Crack Propagation in Cementitious Composites," in International RILEM Conference On Advances In Construction Materials Through Science and Engineering, China (Hong Kong).

Pereira, E. B., Fischer, G., and Barros, J. A. O. (2012). Effect of Hybrid Fiber Reinforcement on the Cracking Process in Fiber Reinforced Cementitious Composites. Cement and Concrete Composites 34, 1114-1123. doi:10.1016/ j.cemconcomp.2012.08.004

Prokopski, G., and Halbiniak, J. (2000). Interfacial Transition Zone in Cementitious Materials. Cement and Concrete Research 30, 579-583. doi:10.1016/s0008-8846(00)00210-6

Pupurs, A. (2012). Micro-Crack Initiation and Propagation in Fiber Reinforced Composites. Luleå tekniska universitet: $\mathrm{PhD}$ Degree $\mathrm{PhD}$ thesis.

Qiu, J., Luo, L., Li, X., Li, D., Chen, Y., and Luo, Y. (2020). Numerical Investigation on the Tensile Fracturing Behavior of Rock-Shotcrete Interface Based on Discrete Element Method. International Journal of Mining Science and Technology 30, 293-301. doi:10.1016/j.ijmst.2020.03.007

Ramesh, K., Seshu, D. R., and Prabhakar, M. (2003). Constitutive Behaviour of Confined Fibre Reinforced Concrete under Axial Compression. Cement and Concrete Composites 25, 343-350. doi:10.1016/s0958-9465(02)00051-3

Rena, C.Y., Cifuentes, H., Rivero, I., Ruiz, G., and Zhang, X. (2016). Dynamic Fracture Behaviour in Fibre-Reinforced Cementitious Composites. Journal of the Mechanics and Physics of Solids 93, 135-152.

Scrivener, K. L., Crumbie, A. K., and Laugesen, P. (2004). The Interfacial Transition Zone (Itz) between Cement Paste and Aggregate in Concrete. Interface Science 12, 411-421. doi:10.1023/b:ints.0000042339.92990.4c

Siva, C. R., and Pankaj, A. (2019). Flexural Behavior of Reinforced Concrete Beams with High Performance Fiber Reinforced Cementitious Composites. J. Cent. South Univ. 26, 2609-2622. doi:10.1007/s11771-019-4198-0

Sjölander, A., Hellgren, R., Malm, R., and Ansell, A. (2020). Verification of Failure Mechanisms and Design Philosophy for a Bolt-Anchored and Fibre-Reinforced Shotcrete Lining. Engineering Failure Analysis 116, 104741. doi:10.1016/ j.engfailanal.2020.104741

Soulioti, D., Barkoula, N. M., Paipetis, A., Matikas, T. E., Shiotani, T., and Aggelis, D. G. (2009). Acoustic Emission Behavior of Steel Fibre Reinforced Concrete under Bending. Construction and Building Materials 23, 3532-3536. doi:10.1016/j.conbuildmat.2009.06.042

Tahenni, T., Chemrouk, M., and Lecompte, T. (2016). Effect of Steel Fibers on the Shear Behavior of High Strength Concrete Beams. Construction and Building Materials 105, 14-28. doi:10.1016/j.conbuildmat.2015.12.010

Toé Casagrande, M. D., Coop, M. R., and Consoli, N. C. (2006). Behavior of a Fiber-Reinforced Bentonite at Large Shear Displacements. J. Geotech. Geoenviron. Eng. 132, 1505-1508. doi:10.1061/(asce)1090-0241(2006)132: 11(1505)

Trainor, K. J., Foust, B. W., and Landis, E. N. (2013). Measurement of Energy Dissipation Mechanisms in Fracture of Fiber-Reinforced Ultrahigh-Strength Cement-Based Composites. J. Eng. Mech. 139, 771-779. doi:10.1061/(asce) em.1943-7889.0000545

Wang, P., Zhao, M., Du, X., and Liu, J. (2019). Dynamic Response of Bridge Pier under Combined Earthquake and Wave-Current Action. J. Bridge Eng. 24, 04019095. doi:10.1061/(asce)be.1943-5592.0001471

Wang, S., Xu, L., Yin, C., Chen, Z., and Chi, Y. (2021a). Experimental Investigation on the Damage Behavior of Ultra-High Performance Concrete Subjected to Cyclic Compression. Composite Structures 267, 113855. doi:10.1016/ j.compstruct.2021.113855

Wang, Y., Cao, Y., Cui, L., Si, Z., and Wang, H. (2020). Effect of External Sulfate Attack on the Mechanical Behavior of Cemented Paste Backfill. Construction and Building Materials 263, 120968. doi:10.1016/j.conbuildmat.2020.120968 
Wang, Z.-C., Duan, D.-Y., Wang, S.-H., Mo, Y., and Yin, Y.-G. (2021b). Mechanical Behavior of the Novel Gradient Concrete Tower of a CableStayed Bridge. Frontiers in Materials 8. doi:10.3389/fmats.2021.676440

Wu, D., Liu, Y.-C., Zheng, Z.-X., and Wang, S. (2016). Impact Energy Absorption Behavior of Cemented Coal Gangue-Fly Ash Backfill. Geotech Geol Eng 34, 471-480. doi:10.1007/s10706-015-9958-5

Wu, D., Zhao, R., and Qu, C. (2019). Effect of Curing Temperature on Mechanical Performance and Acoustic Emission Properties of Cemented Coal Gangue-Fly Ash Backfill. Geotech Geol Eng 37, 3241-3253. doi:10.1007/ s10706-019-00839-8

Xu, L., Li, B., Chi, Y., Li, C., Huang, B., and Shi, Y. (2018a). Stress-Strain Relation of Steel-Polypropylene-Blended Fiber-Reinforced Concrete under Uniaxial Cyclic Compression. Advances in Materials Science and Engineering 2018, 9174943. doi:10.1155/2018/9174943

Xu, L., Li, B., Ding, X., Chi, Y., Li, C., Huang, B., and Shi, Y. (2018b). Experimental Investigation on Damage Behavior of Polypropylene Fiber Reinforced Concrete under Compression. Int J Concr Struct Mater 12, 68. doi:10.1186/s40069-0180302-3

Xu, W.-B., Liu, B., and Wu, W.-L. (2020). Strength and Deformation Behaviors of Cemented Tailings Backfill under Triaxial Compression. J. Cent. South Univ. 27, 3531-3543. doi:10.1007/s11771-020-4568-7

$\mathrm{Xu}, \mathrm{W}$., Li, Q., and Zhang, Y. (2019). Influence of Temperature on Compressive Strength, Microstructure Properties and Failure Pattern of Fiber-Reinforced Cemented Tailings Backfill. Construction and Building Materials 222, 776-785. doi:10.1016/j.conbuildmat.2019.06.203

Xue, G., Yilmaz, E., Feng, G., Cao, S., and Sun, L. (2021). Reinforcement Effect of Polypropylene Fiber on Dynamic Properties of Cemented Tailings Backfill under Shpb Impact Loading. Construction and Building Materials 279, 122417. doi:10.1016/j.conbuildmat.2021.122417

Xue, G., Yilmaz, E., Song, W., and Cao, S. (2019). Mechanical, Flexural and Microstructural Properties of Cement-Tailings Matrix Composites: Effects of Fiber Type and Dosage. Composites Part B: Engineering 172, 131-142. doi:10.1016/j.compositesb.2019.05.039

Yilmaz, E. (2018). Stope Depth Effect on Field Behaviour and Performance of Cemented Paste Backfills. International Journal of Mining, Reclamation and Environment 32, 273-296. doi:10.1080/ 17480930.2017.1285858

Ying, M., and Jin-Xin, G. (2018). Seismic Failure Modes and Deformation Capacity of Reinforced Concrete Columns under Cyclic Loads. Periodica Polytechnica Civil Engineering 62, 80-91. doi:10.3311/ppci.9893
Yu, K.-Q., Yu, J.-T., Dai, J.-G., Lu, Z.-D., and Shah, S. P. (2018). Development of Ultra-High Performance Engineered Cementitious Composites Using Polyethylene (Pe) Fibers. Construction and Building Materials 158, 217-227. doi:10.1016/j.conbuildmat.2017.10.040

Yu, K., Ding, Y., Liu, J., and Bai, Y. (2020). Energy Dissipation Characteristics of All-Grade Polyethylene Fiber-Reinforced Engineered Cementitious Composites (Pe-Ecc). Cement and Concrete Composites 106, 103459. doi:10.1016/j.cemconcomp.2019.103459

Yun, H.-D., Yang, I.-S., Kim, S.-W., Jeon, E., Choi, C.-S., and Fukuyama, H. (2007). Mechanical Properties of High-Performance Hybrid-Fibre-Reinforced Cementitious Composites (Hphfrccs). Magazine of Concrete Research 59, 257-271. doi:10.1680/macr.2007.59.4.257

Yuyama, S., Li, Z.-W., Ito, Y., and Arazoe, M. (1999). Quantitative Analysis of Fracture Process in Rc Column Foundation by Moment Tensor Analysis of Acoustic Emission. Construction and Building Materials 13, 87-97. doi:10.1016/s0950-0618(99)00011-2

Zhou, J., Pan, J., and Leung, C. K. Y. (2015). Mechanical Behavior of FiberReinforced Engineered Cementitious Composites in Uniaxial Compression. J. Mater. Civ. Eng. 27, 04014111. doi:10.1061/(asce)mt.1943-5533.0001034

Zhou, Y., Zhong, Q., Xing, F., Sui, L., Huang, Z., and Guo, M. (2020). Influence of Cyclic Loading on the Tensile Fracture Characteristics of Ultra-High Performance Engineered Cementitious Composites. Construction and Building Materials 240, 117937. doi:10.1016/j.conbuildmat.2019.117937

Conflict of Interest: The authors declare that the research was conducted in the absence of any commercial or financial relationships that could be construed as a potential conflict of interest.

Publisher's Note: All claims expressed in this article are solely those of the authors and do not necessarily represent those of their affiliated organizations, or those of the publisher, the editors, and the reviewers. Any product that may be evaluated in this article, or claim that may be made by its manufacturer, is not guaranteed or endorsed by the publisher.

Copyright (C) 2021 McLean and Cui. This is an open-access article distributed under the terms of the Creative Commons Attribution License (CC BY). The use, distribution or reproduction in other forums is permitted, provided the original author(s) and the copyright owner(s) are credited and that the original publication in this journal is cited, in accordance with accepted academic practice. No use, distribution or reproduction is permitted which does not comply with these terms. 